ERRATUM

\title{
Erratum to: A Missed Opportunity
}

\author{
Ryan Van Wert, $M D^{7}$, Ann Marie McKenna, $M D^{7}$, Christopher A. Smith, MD, \\ Peter Vadas, MD, $P h D^{7}$, Allan S. Detsky, MD, PhD ${ }^{3,4}$, and Ophyr Mourad, MD, MSc ${ }^{7}$ \\ 'Department of Medicine, St. Michael's Hospital, University of Toronto, Toronto, ON, Canada; ${ }^{2}$ Department of Medicine, Queens University, \\ Kingston, ON, Canada; ${ }^{3}$ Departments of Medicine and Health Policy Management and Evaluation, University of Toronto, Toronto, ON, \\ Canada; ${ }^{4}$ Department of Medicine, Mount Sinai Hospital, University of Toronto, Toronto, ON, Canada.
}

J Gen Intern Med 28(3):487

DOI: $10.1007 / \mathrm{s} 11606-012-2293-0$

(c) Society of General Internal Medicine 2012

\section{Erratum to: J Gen Intern Med DOI 10.1007/s11606-012-2248-5}

T $\mathrm{n}$ the original publication, the affiliations of the fifth 1 author, Allan S. Detsky, are incorrectly given as: ${ }^{3}$ Department of Medicine, St. Michael's Hospital, University of Toronto and University Health Network, Toronto, ON, Canada; ${ }^{4}$ Department of Medicine and Health Policy Management and Evaluation, Mount Sinai Hospital, Toronto, ON, Canada. The correct affiliations are: ${ }^{3}$ Departments of Medicine and Health Policy Management and Evaluation, University of Toronto, Toronto, ON, Canada; ${ }^{4}$ The Department of Medicine, Mount Sinai Hospital, University of Toronto, ON, Canada. The publisher regrets the error.

Corresponding Author: Ophyr Mourad, MD, MSc; Department of Medicine, St. Michael's Hospital, University of Toronto, 30 Bond Street, Toronto, ON, Canada M5B 1W8 (e-mail: mourado@smh.ca).

The online version of the original article can be found at http:// dx.doi.org10.1007/s11606-012-2248-5.

Published online 20 December 2012 